\title{
EVALUATION OF BIOMARKERS FOLLOWING AUTOLOGOUS OSTEOCHONDRAL TRANSPLANTATION IN THE EQUINE STIFLE JOINT - AN EXPERIMENTAL STUDY
}

\author{
Pál TUSKA ${ }^{1}$, Balázs TÓTH ${ }^{1}$, Gábor VÁSÁRHELYI ${ }^{2}$, László HANGODY ${ }^{2}$, Miklós PAPP $^{3}$ \\ and Gábor BoDÓ ${ }^{1 *}$
}

${ }^{1}$ Department and Clinic of Equine Medicine, Faculty of Veterinary Science, Szent István University, H-2225 Üllö, Dóra major, Hungary; ${ }^{2}$ Orthopaedics and Trauma Department, Uzsoki Hospital, Budapest, Hungary; ${ }^{3}$ Department of Orthopaedic Surgery, Borsod County Teaching Hospital, Miskolc, Hungary

(Received 19 January 2015; accepted 4 May 2016)

\begin{abstract}
The purpose of this study was to evaluate changes in biomarker and synovial parameters following autologous osteochondral transplantation (AOT) in the equine stifle joint, to test the hypothesis whether synovial parameters would show significant differences at selected time points following the surgery (at days 3, 14, 60 and 180) compared to baseline level (at day 0). Surgical intervention was performed in both stifles of nine horses $(n=18)$. The joints were randomly assigned to operated and sham-operated groups. Grafts $8.5 \mathrm{~mm}$ in diameter were harvested from the femoropatellar (FP) joint under arthroscopic control and the medial femorotibial (MFT) joints had AOT using mosaicplasty (MP) instrumentation, while the sham FP and sham MFT joints underwent arthroscopy and miniarthrotomy without transplantation, respectively. Synovial fluid (SF) parameters were evaluated at days 4, 14, 60 and 180. Data were analysed by two-way repeated-measures analysis of variance (ANOVA), and $\mathrm{P}<0.05$ was considered significant. During the first 10-14 days after surgery, lameness of degree 2-3/5 [American Association of Equine Practitioners (AAEP) scores] was present, which disappeared after 60 days. Joints with transplantation showed significant increases in synovial white blood cell count (WBC), total protein (TP), substance P, C1,2C and CS846 epitope concentration at day 3 compared to baseline and shamoperated joints $(\mathrm{P}<0.05)$. These parameters returned to the baseline values by two months after surgery and remained within normal levels at 6 months postoperatively.
\end{abstract} lage

Key words: Stifle, horse, joint, biomarker, mosaicplasty, synovium, carti-

Lesions on the weight-bearing surface frequently occur in the equine medial femoral condyle (MFC) and may cause lameness. Such lesions are often

*Corresponding author; E-mail: Bodo.Gabor@aotk.szie.hu; Phone: 0036 (29) 521-304; Fax: 0036 (29) 521-303 
caused by trauma. The most frequent lesions involve fissures, fibrillation or ulceration of the surface or subchondral bone cysts (SBC) at that location. In both human and equine patients, focal cartilaginous lesions can originate from chondropathy or chondral trauma and are difficult to treat and manage, especially on weight-bearing joint surfaces (Hangody et al., 2010; Nixon et al., 2011). When such lesions are left untreated, the biomechanical protective function of cartilage declines, subsequently leading to a loss of joint function (Buckwalter and Mankin, 1998) and predisposing the joint to the development of osteoarthritis (OA) (Malda et al., 2012). Depending on the location and extent of lesions, surgical treatment is often recommended, especially in cases that are refractory to conservative management.

Autologous osteochondral transplantation (AOT) using the mosaicplasty (MP) method has become one of the worldwide accepted techniques for resurfacing damaged joint surfaces of up to $1-4 \mathrm{~cm}^{2}$ even in elite athletes (Hangody et al., 2010). Equine clinical studies in the stifle (Bodó et al., 2000; Bodó et al., 2004) and hock (Janicek et al., 2010) as well as experimental studies (Bodó et al., 2014) using the MP method have demonstrated favourable outcomes with this method.

Although the use of biomarkers to detect disease is a relatively new technique, it has already been demonstrated to provide reliable results at an early stage of a disorder. Biomarkers have been employed to date in experimental equine studies (Billinghurst et al., 1997; Frisbie et al., 1999; Laverty et al., 2000; Celeste et al., 2005) and are a promising tool for diagnostic purposes (de Grauw et al., 2006). As the early detection of a joint disease is crucial for the outcome of treatment, the use of biomarkers is a great tool (Van Weeren and Firth, 2008). A biomarker is a parameter that can be measured objectively and evaluated as an indicator of normal physiological or pathological functions and processes (Biomarkers Definitions Working Group, 2001). Direct markers are indicators of increased or abnormal anabolic or catabolic activity related to constituents of the extracellular matrix (ECM) of musculoskeletal tissues. Indirect markers, however, are not components of the ECM but may act on ECM metabolism and, therefore, have an indirect influence on tissue integrity. The best candidates for biomarkers in osteoarthritis are most likely to be structural molecules or fragments linked to cartilage, bone or synovium and may be specific to one type of joint tissue or common to them all. They may represent tissue degradation or tissue synthesis and may be measured in synovial fluid, blood or urine (Lotz et al., 2013).

The chondroitin sulphate (CS) 846 (CS846) epitope is an indicator of large or fetal-like aggrecan synthesis. This epitope is only present on the largest aggrecan molecules and was originally identified in human fetal cartilage; its content decreases considerably with cessation of growth (Glant et al., 1986). Degraded aggrecan molecules containing CS846 epitopes released from the matrix into the SF are detectable by immunoassay and indicative of aggrecan turnover (Frisbie 
et al., 1999; Laverty et al., 2000; Thonar and Manicourt, 2001). This epitope reappears in adult cartilage in joints with osteochondritis dissecans (OCD) and is believed to get elevated in an attempt at repair (Frisbie et al., 1999). Increases in CS846 epitope in synovial fluid (SF) are seen after injury but this epitope also reappears in cartilage in the largest aggrecan molecules in the presence of osteoarthritis (OA) (Rikzalla el al., 1992; Lohmander et al., 1999). In OA, CS846 epitope concentrations in cartilage correlate with those in SF. Thus, increases of the CS846 epitope in cartilage and SF suggest an increase in aggrecan synthesis (Laverty et al., 2000).

Type II collagen is the principal triple helical collagen of articular cartilage. The degradation of mature type II collagen fibrils is collagenase dependent. The product of the primary initiating event of this cleavage can be measured by immunoassay of a C1,2C neoepitope (Billinghurst et al., 1997; Poole et al., 2003; Celeste et al., 2005). This assay detects not only the cleavage of type II collagen but also that of type I collagen present in the synovium, joint capsule, and ligaments (Billinghurst et al., 1997; Celeste et al., 2005). The levels of C1,2C in, and its release from, cartilage is increased in OA (Billinghurst et al., 1997).

Substance $\mathrm{P}$ is a bioactive 11-amino-acid oligopeptide mediator that is released into SF from articular-type $\mathrm{C}$ nerve fibres in response to mechanical or chemical stimulation (Levine and Taiwo, 1989; Caron et al., 1992). Nerve fibres containing substance $\mathrm{P}$ have been demonstrated in the equine synovial membrane and subchondral bone, and multiple studies have identified elevated synovial fluid concentrations of substance $\mathrm{P}$ in arthritic equine joints as compared to normal ones (Caron et al., 1992; Nixon and Cummings, 1994; Fortier and Nixon, 1997; Kirker-Head et al., 2000). Substance P is associated with clinically detectable joint pain in the horse (de Grauw et al., 2006).

Several methods have been described in the equine literature to evaluate outcome measures of different articular resurfacing techniques, including postoperative clinical assessment, long-term follow-up with owner questionnaires, radiological follow-up of the affected joints, follow-up arthroscopies, and anteor postmortem histological evaluation of the transplanted area (Kold and Hickman, 1984; Howard et al., 1995; Bodó et al., 2000; Jackson et al., 2000; Hurtig et al., 2001; Sandler et al., 2002; Bodó et al., 2004; Wallis et al., 2008; Janicek et al., 2010; Nixon et al., 2011; Ortved et al., 2011; Malda et al., 2012; Bodó et al., 2014; Santschi et al., 2015). However, to the best of the authors' knowledge, no data are available on the evaluation of synovial biomarkers and basic parameters following AOT in humans or horses.

The objective of this study was to explore donor (FP), recipient (MFC) and sham-operated joints in order to gain more information about postoperative processes following MP in the equine stifle joint. Our hypothesis was that synovial parameters would show significant differences at different time points after the surgery (at days 3, 14, 60 and 180) compared to baseline level (day 0). 


\section{Materials and methods}

\section{Experimental animals}

Nine skeletally mature warmblood horses (two stallions, one mare and six geldings), with an age range of 3 to 10 years (mean \pm SD: $6.55 \pm 2.3$ ) and no history of orthopaedic disease, were enrolled in the study. Prior to enrolment the horses underwent a detailed lameness examination and radiological evaluation of the stifles. In full compliance with the Act on Animal Experiments, this study was evaluated and approved by the Ethics Committee of the Pest County Bureau for Animal Health.

\section{Surgical procedure and experimental design}

Antibiotics (amoxicillin trihydrate $5.6 \mathrm{mg} / \mathrm{kg}$ and potassium clavulanate $1.4 \mathrm{mg} / \mathrm{kg}$, Noroclav Inj., Norbook Ltd.) im. and $2.2 \mathrm{mg} / \mathrm{kg}$ phenylbutazone iv. were given to the horses prior to surgery.

Both stifle joints of the nine horses were randomly assigned to either a transplanted $(n=14)$ or a sham $(n=4)$ group. The medial femoral trochlea was used as donor site in the transplanted group. Two cylindrical osteochondral grafts ( $8.5 \mathrm{~mm}$ in diameter and $25-30 \mathrm{~mm}$ in length) were harvested under arthroscopic guidance using the arthroscopic approach described previously (Bodó et al., 2014). The same limb was flexed after the harvesting procedure. Transplantation into the MFC was carried out by conventional arthrotomy (Bodó et al., 2014). One graft, $20 \mathrm{~mm}$ in length, was transplanted into the weight-bearing surface of the MFC. Closure of the surgical wound was performed in four layers. Mosaicplasty instrumentation adapted to equine joints was provided by Metrimed Ltd. (Hódmezővásárhely, Hungary).

Arthroscopic evaluation as well as mini-arthrotomy $(1 \mathrm{~cm}$ in length) for the tubular chisel were performed for the sham-operated FP joints without harvesting the grafts. For the sham-operated recipient joints the same arthrotomic wound was created as during AOT, the MFC was visualised, and the wound was closed in four layers. All surgeries were performed by the same surgeon (GB).

\section{Postoperative care}

Horses were box-rested for 3 weeks followed by a 5- to $10-\mathrm{min} /$ day hand walk for further eight weeks. After this 11-week postoperative period they were turned out in small paddocks. Oral phenylbutazone $(1.1 \mathrm{mg} / \mathrm{kg}$ once daily) was administered for 4-7 days after the operation. For each horse, clinical examinations were performed prior to day 0 and then throughout the study period. Radiographs were taken six months after the surgeries. 


\section{Collection of synovial fluid}

Samples were collected from the FP and MFT joints before surgery (day 0) and on days 3, 14, 60 and 180 postoperatively. Three $\mathrm{ml}$ of SF were transferred in EDTA tubes for macroscopic evaluation, white blood cell (WBC) count and total protein measurements, while the remainder was centrifuged in serum tubes at $13,000 \mathrm{rpm}$ for $15 \mathrm{~min}$, aliquoted and stored at $-80^{\circ} \mathrm{C}$ until further analysis.

\section{Biomarker assays}

Substance $\mathrm{P}$ was measured using a commercial enzyme immunoassay kit (Cayman Chemical, Ann Arbor, MI, USA). The concentrations of C1,2C and CS846 epitopes were measured using competitive ELISA kits (IBEX, Montreal, Québec, Canada). A plate reader (BioTek 8000LX, Biotek Inc., USA) was used to measure the optical density (OD). The OD of substance $\mathrm{P}$ was measured at $405 \mathrm{~nm}$ while that of epitopes C1,2C and CS846 at $450 \mathrm{~nm}$. Specimens were measured in duplicate and the mean OD was used to determine the concentration after creation of the standard curve for each plate. The concentration was expressed as $\mathrm{pg} / \mathrm{ml}$ (substance $\mathrm{P}$ ), $\mu \mathrm{g} / \mathrm{ml}(\mathrm{C} 1,2 \mathrm{C}$ ), and $\mathrm{ng} / \mathrm{ml}$ (CS846). All assays had been previously validated for use with equine SF (Frisbie et al., 1999; Celeste et al., 2005; de Grauw et al., 2006; Frisbie et al., 2008; Piat et al., 2012). The intra- and inter-assay coefficients of variation for the evaluation of these SF biomarkers were all $<5 \%$ or $<13 \%$, respectively.

\section{Statistical analysis}

Statistical analysis was performed with a commercially available programme (www.r-project.org). Distribution of the continuous data was tested with the Shapiro-Wilk test. Descriptive statistical results were expressed as mean \pm $\mathrm{SD}$. A two-way repeated-measures analysis of variance (ANOVA) was used to compare the main effects of the model including time (days 0,3,14, 60 and 180) and treatment (operated, sham). Post-hoc correction was used with the Bonferroni method. Significance was set at $\mathrm{P}<0.05$.

\section{Results}

\section{Clinical assessments}

All horses showed lameness of degree 2-3/5 [American Association of Equine Practitioners (AAEP) scores] in the immediate postoperative period. Joint effusion was also present in both (transplanted or sham-operated MFT and FP) joints, but it abated completely by the second month after surgery. The effusion did not disappear earlier in the sham-operated joints. 
Lameness disappeared in all horses after two months except for one case where an MFT joint became infected after SF collection on day 14 and had to undergo multiple joint lavages and repeated arthroscopic evaluation. This horse showed lameness of $2 / 5$ grade after 8 months. Proximal limb flexion tests were mildly positive for 5 out of the 18 stifles at two months after surgery and became negative four months postoperatively for all joints except the infected MFT joint, for which a mild positivity persisted throughout the study. The results of this joint were removed from all subsequent analyses.

Radiographs were taken after the transplantation. Osteoarthritis was not identified in the stifles with radiographs except for the infected MFT joint, where a mild elongation was observed on the medial condyle of the tibia.

\section{Synovial fluid parameters}

The results of descriptive statistical data are presented in Tables 1 (FP joint) and 2 (MFT joint).

White blood cell count (Tables 1 and 2, Fig. 1). The WBC count was significantly increased in the operated FP joints on day 3 as compared with the sham FP or the operated MFT joints (Fig. 1). When compared with baseline values, all samples were significantly different at day 3. On days 14 and 60 significant differences could be detected only in the sham MFT and operated MFT joints, respectively.

Synovial total protein (TP) (Tables 1 and 2, Fig. 2). A significant increase in TP levels was observed in all joints on day 3 followed by a decline by day 14 . The level of TP returned to normal by day 60 in all joints. No significant differences in TP levels were detected between sham and operated joints at any time point.

Synovial biomarkers (Figs 3, 4 and 5). As compared to day 0 values, on days 3 and 14 there was a significant increase in substance $P$ levels in all joints. No significant differences were observed between sham and operated joints at any time point (Fig. 3). As compared to day 0 values, on day 3 there was a significant increase in $\mathrm{C} 1,2 \mathrm{C}$ concentration in the operated joints and in the shamoperated MFT joint, while the sham-operated FP joint did not show significant differences (Fig. 4). The concentration of CS846 biomarker significantly increased on day 3 in the sham joints and in the operated MFT joint and significantly decreased on day 14 in both types of MFT joints. No significant differences were observed in C1,2C and CS846 values between sham and operated joints at any time point (Figs 4 and 5). 
TUSKA et al.

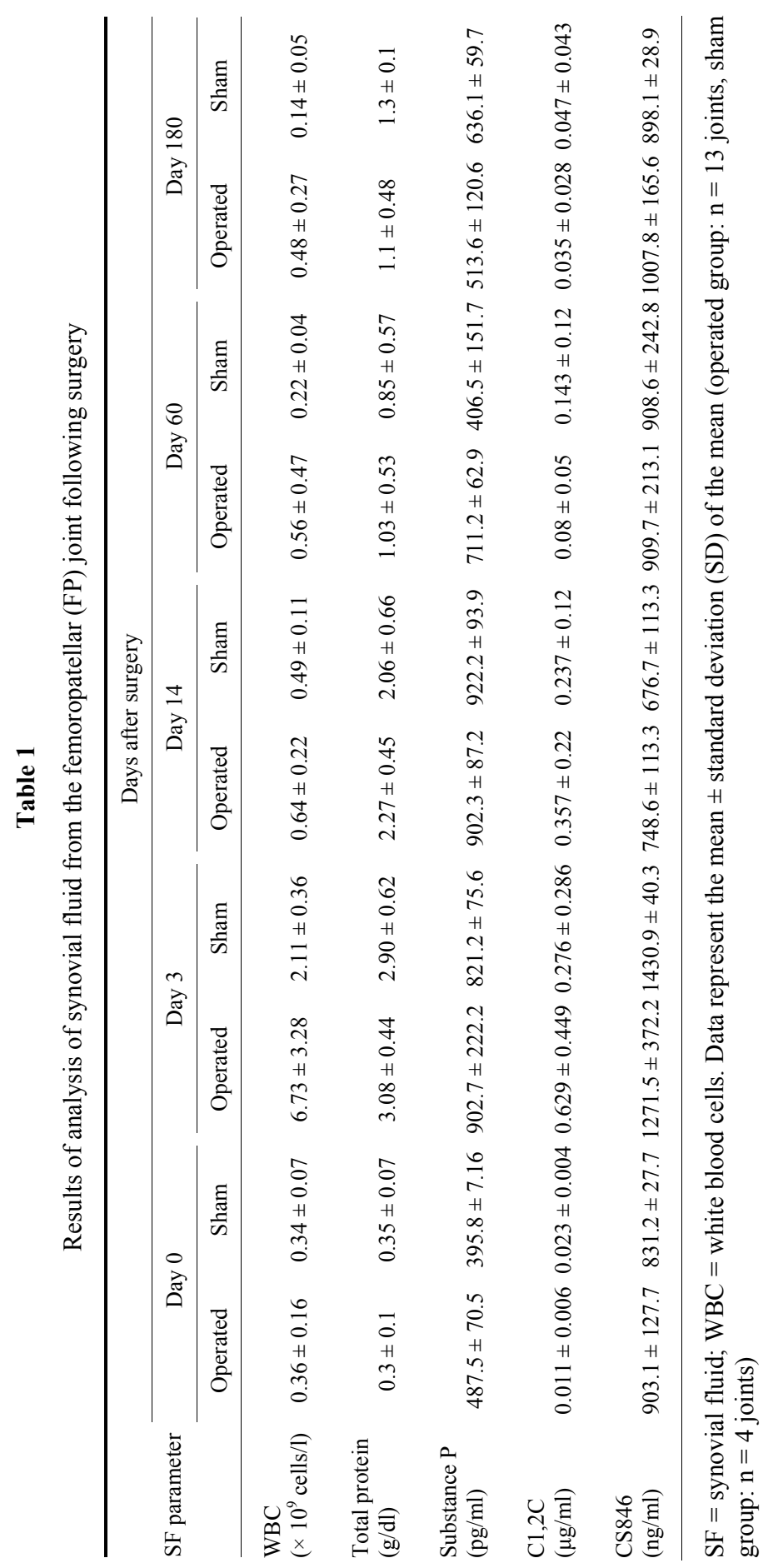


BIOMARKER KINETICS IN AUTOLOGUS OSTEOCHONDRAL TRANSPLANTATION

171

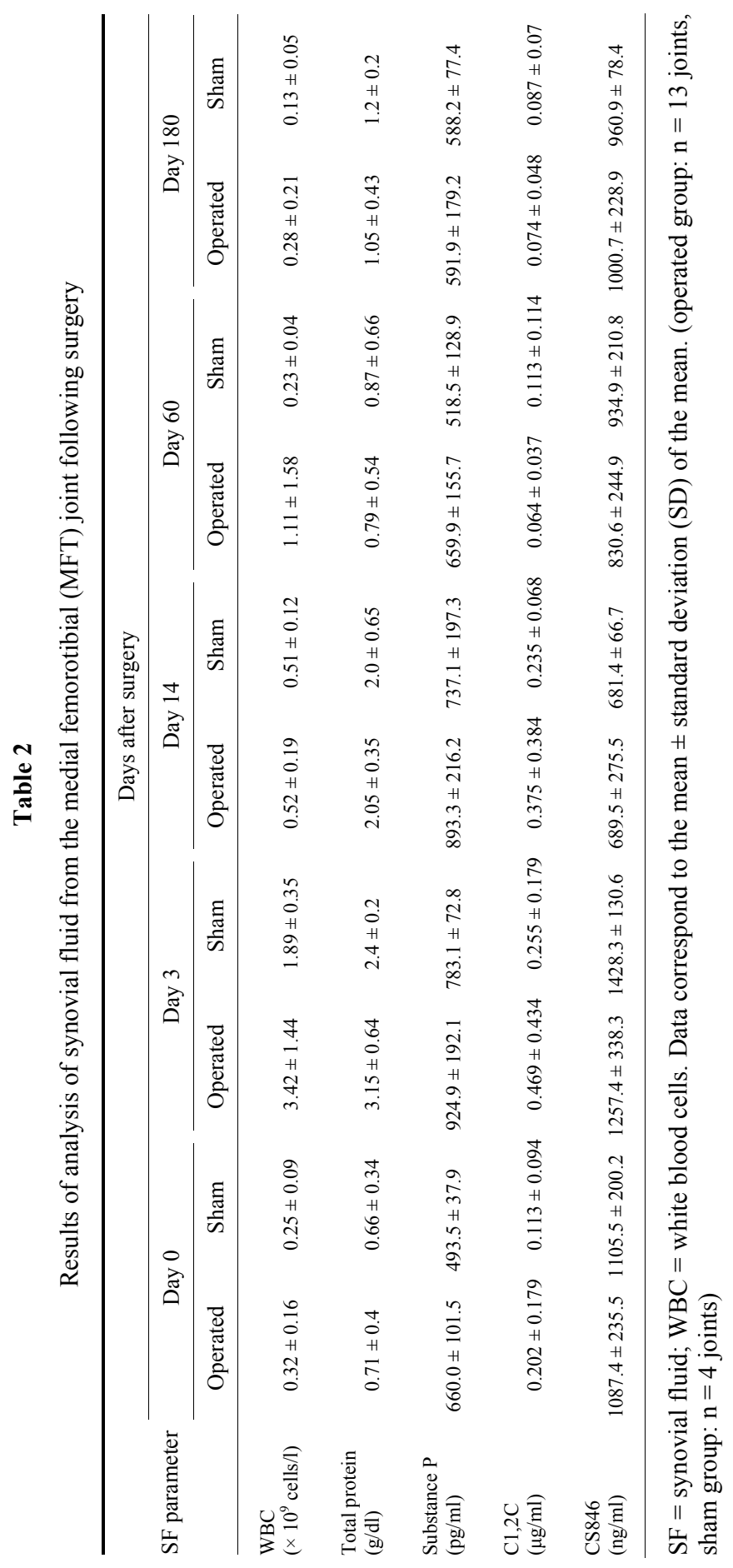


Fig. 1

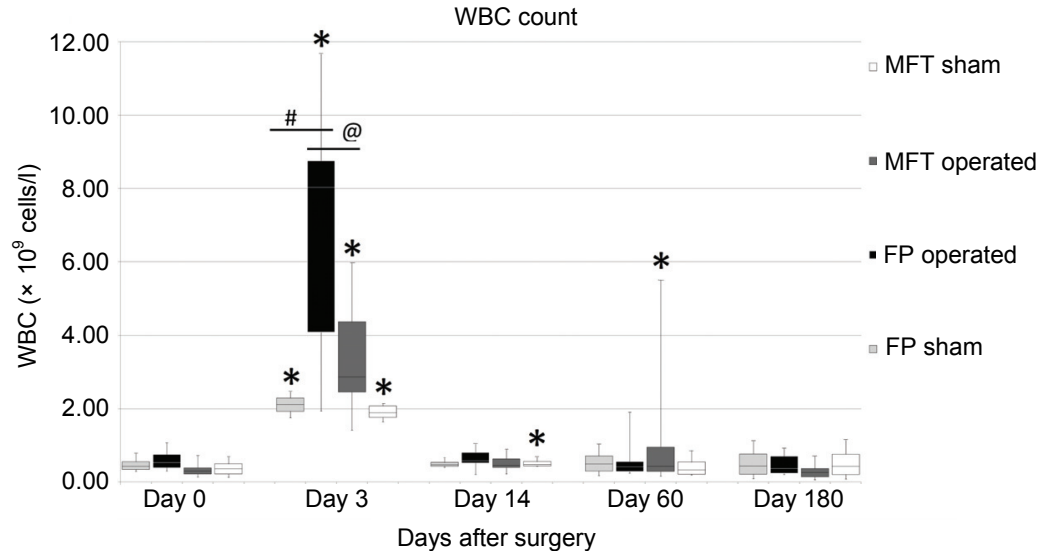

Fig. 2

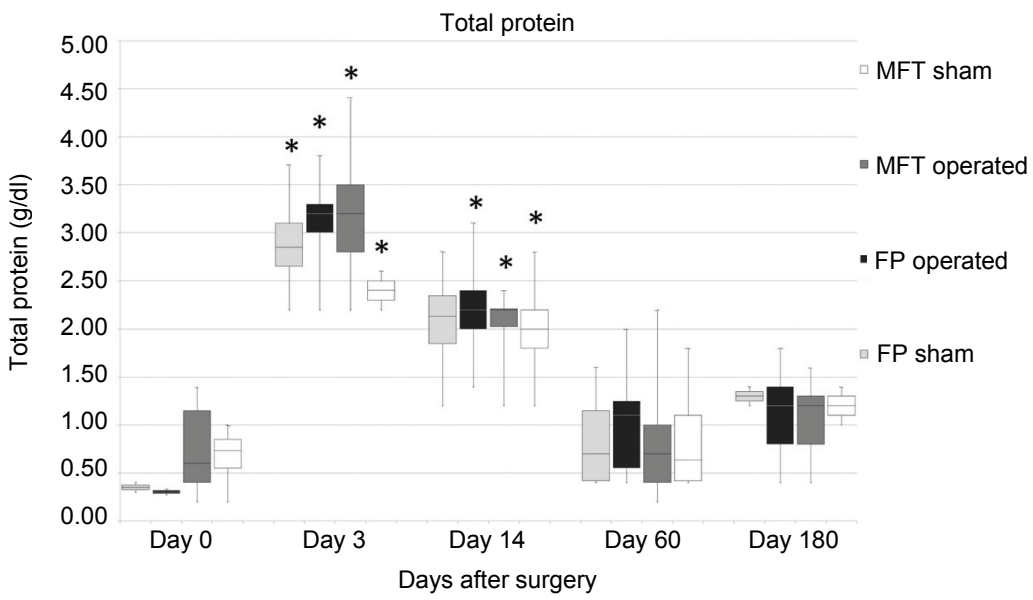

Fig. 3

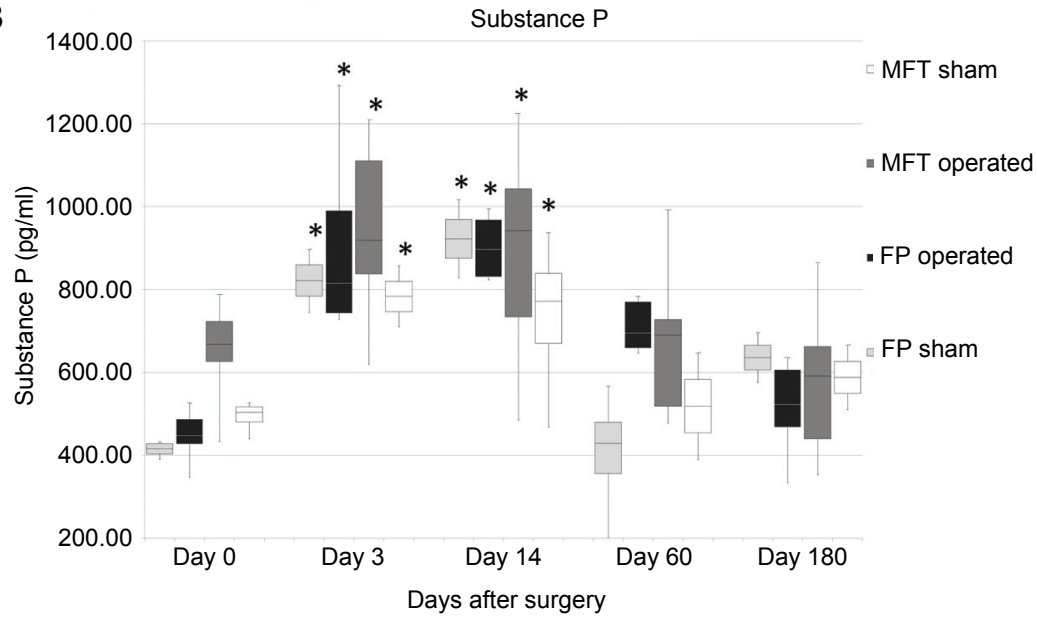


Fig. 4

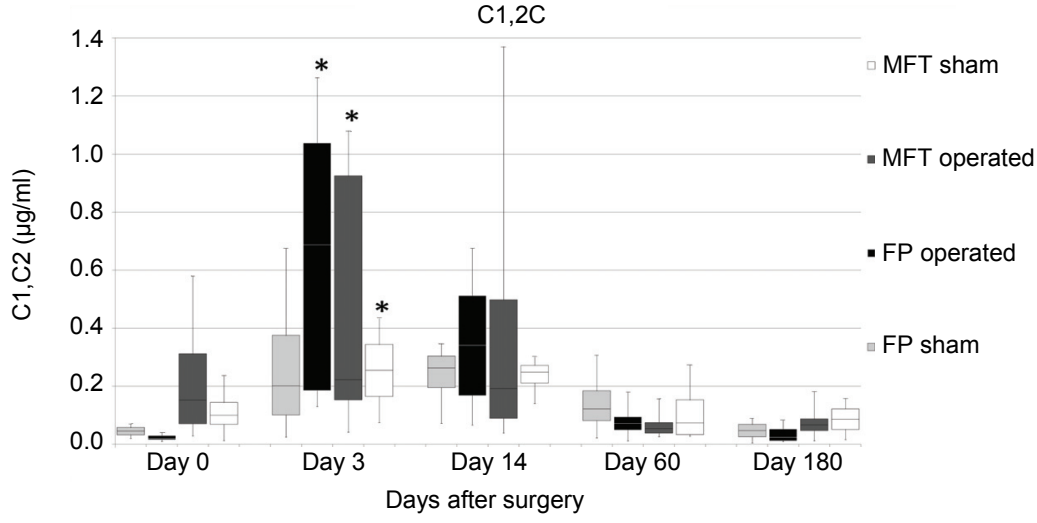

Fig. 5

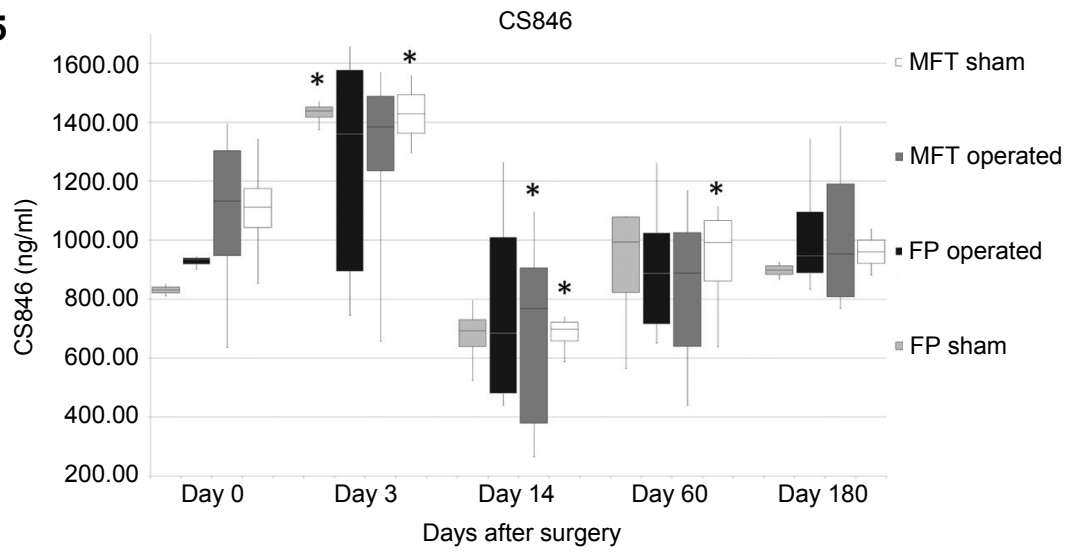

Figs 1-5. Box plot white blood cell (WBC) count (Fig. 1), total protein concentration (Fig. 2) and concentrations of biomarkers Substance P (Fig. 3), C1,2C (Fig. 4) and CS846 (Fig. 5) in the synovial fluid of sham and operated femoropatellar (FP) and medial femorotibial (MFT) joints. Significant differences between the values of sham and operated joints at each time point are indicated by \#. Significant differences between the values of operated MFT and operated FP joints at each time point are indicated by @. Significant differences between baseline and post-treatment values of operated and sham joints are indicated by *. Differences at $\mathrm{P}<0.05$ were considered statistically significant

\section{Discussion}

No significant differences were found between sham-operated joints and joints where harvesting or AOT was performed, except in WBC count at a single time point. This only significant difference between sham-operated FP joints and FP joints with graft harvest was found at day 3 and disappeared by day 14, when the WBC count returned to the baseline level. TP levels were elevated in all four types of joints (sham and operated FP and MFT) without any remarkable differ- 
ences between sham and operated groups. A potential cause of a higher peak in WBC count in the FP joints was the exposed subchondral bone, potentially providing WBCs with easy access to the FP joint from the exposed bone marrow spaces. All things considered, this might be a logical response compared to the MFT joints with a lower WBC count, where the drilled holes were sealed with transplanted osteochondral grafts.

This finding correlates with a similar elevation of $\mathrm{C} 1,2 \mathrm{C}$ biomarkers in the same sham-operated FP joints at day 3. C1,2C measures collagen type I and II degradation products, indicating cartilage degradation (type II collagen) and synovial inflammation (type I collagen) in the joint (Billinghurst et al., 1997; Celeste et al., 2005). This may be explained by the fact that these joint surfaces served as cartilage donors in the experiment and consequently sustained more tissue damage compared to the other joint types (operated FP and MFT and sham MFT), because the graft donor sites remained uncovered. An alternative cause of $\mathrm{C} 1,2 \mathrm{C}$ rise could be the more pronounced synovial inflammation in the operated joints due to type I collagen degradation. However, the TP values, also markers of inflammation, did not corroborate these latter findings. Horses were kept indoors for up to 11 weeks in this study, in contrast to previous studies conducted by the same authors (Bodó et al., 2000, 2004, 2014), where they were let out into paddocks after three weeks. There is still a lack of evidence regarding the best time frame for keeping horses indoors with restricted exercise following AOT of the weight-bearing joint surface. It is known from previous studies that bony union of the transplanted grafts is complete after eight weeks following transplantation in dogs (Hangody et al., 1997). The data collected in this biomarker study support our hypothesis that the first two months seem to be critical also in horses to avoid any further contusion of the transplanted areas. Unfortunately, immediate weight-bearing cannot be avoided in the equine species. Although horses are turned out into paddocks, any quick turn, start or stop can induce further trauma to the transplanted grafts, which might influence integration and fusion of the transplants.

Two major observations were made in this study. First, only subtle changes were noted in most of the SF inflammatory markers (WBC count, TP), all falling within the low inflammatory range (Steel, 2008). The highest concentration of WBC count was $12 \times 10^{9}$ cells $/ 1$ and the highest TP level was $4.5 \mathrm{~g} / \mathrm{dl}$ on day 3. WBC count and TP level stayed under the septic limit during the research except for one case where a MFT joint became infected after SF collection on day 14. Substance P reflects inflammation and pain (de Grauw et al., 2006). This proved to be a sensitive marker in this study, staying on an elevated level after two weeks, and decreasing slowly to the normal level after two months. Its level remained similar in sham-operated and AOT joints, indicating that the trauma caused by AOT did not cause longer-acting pain compared to shamoperated joints. TP values move together with the substance P parameters, because lower inflammation rate reduces the pain in the joint. Second, all of the 
markers showed only temporary changes and returned to normal after a period of two weeks to 2-3 months. The markers remained at the baseline level after six months following AOT, indicating that no signs of osteoarthritic changes were detected in the equine stifle with biomarkers as well as with radiographs six months postoperatively. No evidence of increased collagen degradation was identified in the synovial fluid at 180 days based on $\mathrm{C} 1,2 \mathrm{C}$. In this study, no such changes were detected within six months after transplantation in the FP and MFT joints.

Alterations of the synovial indices in this study were surprisingly subtle, although differences in the synovial WBC count and TP concentrations could be still detected compared to baseline samples. This is a favourable finding, as it indicates that this surgery can be done with an acceptable level of discomfort even when it is performed parallel on both hindlimbs, and no osteoarthritic changes were detected in a six-month postoperative period.

This study had several limitations. It is known that the FP and MFT synovial cavities can communicate in $60-80 \%$ of cases. This means that metabolic changes reflected by synovial parameters in the FP joint will probably be similar those in the MFT joint. It is hard to determine whether changes are due alterations of the donor or the transplanted site. Although the majority of parameters have returned to baseline values, transplantation did not cause lasting changes of the synovial parameters in those joints. Another limitation is the relatively low number of samples.

Taking samples at weekly intervals could have provided more information regarding the subtle changes found between the samples taken in this study. Frisbie et al. (2008) took synovial samples at weekly intervals and found that most of the influence caused by arthrocentesis disappeared after two weeks. On the other hand, taking samples with such frequency could have influenced the data and increased the incidence of iatrogenic (septic) inflammation. This study investigated only three biomarkers, which was due to the limited budget available to us. Investigating more biomarkers could have highlighted further processes occurring in the joint after AOT (Lotz et al., 2013). Horses were turned out into paddocks but did not have controlled exercise, which would have been beneficial for testing the results of this transplantation method. Further follow-up studies are needed to obtain more information about AOT in the long term.

The results of this study are consistent with the findings of previous studies in the equine stifle (Bodó et al., 2014) and show that this transplantation method is a safe technique when performed on the equine medial femoral condyle. We could not detect any signs of incipient osteoarthritic changes with the help of different SF biomarkers and basic synovial parameters during the six-month postoperative period. Osteoarthritic changes were not detected on radiographs six months after the surgeries. In future studies it would be beneficial to perform MRI evaluations of the stifle in order to visualise osteoarthritis in a more sensitive way. A three-month stall confinement with walk on hand after three weeks 
seems to be a safe postoperative period of restricted exercise for horses undergoing such surgery. More exercise could also shed light on the durability of the repair. The results are very encouraging at this six-month time period; however, further longer-term studies are needed as OA is known to be a slowly progressing joint disease.

\section{Acknowledgements}

This research was supported by the European Union and the State of Hungary, cofinanced by the European Social Fund in the framework of TÁMOP-4.2.4.A/ 2-11/12012-0001 'National Excellence Programme' and by the Faculty of Veterinary Science Budapest, KK-UK-2014. We would like to thank Dr. Péter Tóth and Ingelin Bolkesjø for their assistance.

\section{References}

Billinghurst, R. C., Dahlberg, L., Ionescu, M., Reiner, A., Bourne, R., Rorabeck, C., Mitchell, P., Hambor, J., Diekmann, O., Tschesche, H., Chen, J., Van Wart, H. and Poole, A. R. (1997): Enhanced cleavage of type II collagen by collagenases in osteoarthritic articular cartilage. J. Clin. Invest. 99, 1534-1535.

Biomarkers Definitions Working Group (2001): Biomarkers and surrogate endpoints: preferred definitions and conceptual framework. Clin. Pharmacol. Ther. 69, 89-95.

Bodó, G., Hangody, L., Módis, L. and Hurtig, M. (2004): Autologous osteochondral grafting (mosaic arthroplasty) for treatment of subchondral cystic lesions in the equine stifle and fetlock joints. Vet. Surg. 33, 588-596.

Bodó, G., Hangody, L., Szabó, Zs., Peham, Ch., Schinzel, M., Girtler, D. and Sótonyi, P. (2000): Arthroscopic autologous osteochondral mosaicplasty for the treatment of subchondral cystic lesion in the medial femoral condyle in a horse. Acta Vet. Hung. 48, 343-354.

Bodó, G., Vásárhelyi, G., Hangody, L. and Módis, L. (2014): Mosaic arthroplasty of the medial femoral condyle in horses - an experimental study. Acta Vet. Hung. 62, 155-168.

Buckwalter, J. A. and Mankin, H. J. (1998): Articular cartilage: degeneration and osteoarthritis, repair, regeneration and transplantation. Instr. Course Lect. 47, 487-504.

Caron, J. P., Bowker, R. M., Abhold, R. H., Toppin, D. S., Sonea, I. M. and Vex, K. B. (1992): Substance $\mathrm{P}$ in the synovial membrane and fluid of the equine middle carpal joint. Equine Vet. J. 24, 364-366.

Celeste, C., Ionescu, M., Robin, P. A. and Laverty, S. (2005): Repeated intraarticular injections of triamcinolone acetonide alter cartilage matrix metabolism measured by biomarkers in synovial fluid. J. Orthop. Res. 23, 602-610.

de Grauw, J. C., van de Lest, C. H. A., van Weeren, R., Brommer, H. and Brama, P. A. (2006): Arthrogenic lameness of the fetlock: synovial fluid markers of inflammation and cartilage turnover in relation to clinical joint pain. Equine Vet. J. 38, 305-311.

Fortier, L. A. and Nixon, A. J. (1997): Distributional changes in substance P nociceptive fiber patterns in naturally osteoarthritic articulations. J. Rheumatol. 24, 524-530.

Frisbie, D. D., Ray, C. S., Ionescu, M., Poole, A. R., Chapman, P. L. and McIlwraith, C. W. (1999): Measurement of synovial fluid and serum concentrations of the 846 epitope of chondroitin sulfate and of carboxy propeptides of type II procollagen for diagnosis of osteochondral fragmentation in horses. Am. J. Vet. Res. 60, 306-309. 
Frisbie, D. D., Al-Sobayil, F., Billinghurst, R. C., Kawcak, C. E. and McIlwraith, C. W. (2008): Changes in synovial fluid and serum biomarkers with exercise and early osteoarthritis in horses. Osteoarthr. Cartil. 16, 1196-1204.

Glant, T. T., Mikecz, K., Roughley, P. J., Buzás, E. and Poole, A. R. (1986): Age-related changes in protein-related epitopes of human articular-cartilage proteoglycans. Biochem. J. 236, 71-75.

Hangody, L., Dobos, J., Balo, E., Panics, G., Hangody, R. L. and Berkes, I. (2010): Clinical experiences with autologous osteochondral mosaicplasty in an athletic population. Am. J. Sports Med. 38, 1125-1133.

Hangody, L., Kish, G., Kárpáti, Z., Szerb, I., Udvarhelyi, I., Toth, J., Diószegi, Z. and Kendik, Zs. (1997): Autogenous osteochondral graft technique for replacing knee cartilage defects in dogs. Orthopedics International Edition 5, 175-181.

Howard, R. D., McIlwraith, C. W. and Trotter, G. W. (1995): Arthroscopic surgery for subchondral cystic lesions of the medial femoral condyle in horses: 41 cases (1988-1991). J. Am. Vet. Med. Assoc. 206, 842-850.

Hurtig, M., Pearce, S., Warren, S., Kalra, M. and Miniaci, A. (2001): Arthroscopic mosaic arthroplasty in the equine third carpal bone. Vet. Surg. 30, 228-239.

Jackson, W. A., Stick, J. A., Arnoczky, S. P. and Nickels, F. A. (2000): The effect of compacted cancellous bone grafting on the healing of subchondral bone defects of the medial femoral condyle in horses. Vet. Surg. 29, 8-16.

Janicek, J. C., Cook, J. L., Wilson, D. A. and Ketzner, K. M. (2010): Multiple osteochondral autografts for treatment of a medial trochlear ridge subchondral cystic lesion in the equine tarsus. Vet. Surg. 39, 95-100.

Kirker-Head, C. A., Chanda, V. K., Agarwal, R. K., Morris, E. A., Tidwell, A., O'Callaghan, M. W., Rand, W. and Kumar, M. S. (2000): Concentrations of substance P and prostaglandin E2 in synovial fluid of normal and abnormal joints of horses. Am. J. Vet. Res. 61, 714-718.

Kold, S. E. and Hickman, J. (1984): Results of treatment of subchondral bone cysts in the medial condyle of the equine femur with an autogenous cancellous bone graft. Equine Vet. J. 16, 414-418.

Laverty, S., Ionescu, M. and Marcoux, M. (2000): Alternations in cartilage type-II procollagen and aggrecan contents in synovial fluid in equine osteochondrosis. J. Orthop. Res. 18, 399-405.

Levine, J. D. and Taiwo, Y. O. (1989): Involvement of the mu-opiate receptor in peripheral analgesia. Neuroscience 32, 571-575.

Lohmander, L. S., Ionescu, M. and Jugessur, H. (1999): Changes in joint cartilage aggrecan after knee surgery and in osteoarthritis. Arthritis Rheum. 42, 534-544.

Lotz, M., Martel-Pelletier, J., Christiansen, C., Brandi, M-L., Bruyére, O., Chapurlat, R., Collette, J., Cooper, C., Giacovelli, G., Kanis, J. A., Karsdal, M. A., Kraus, V., Lems, W. F., Meulenbelt, I., Pelletier, J-P., Raynauld, J-P., Reiter-Niesert, S., Rizzoli, R., Sandell, L. J., Van Spil, W. E. and Reginster, J-Y. (2013): Value of biomarkers in osteoarthritis: current status and perspectives. Ann. Rheum. Dis. 72, 1756-1763.

Malda, J., Benders, K. E. M., Klein, T. J., de Grauw, J. C., Kik, M. J. L., Hutmacher, D. W., Saris, D. B. F., van Weeren, P. R. and Dher, W. J. A. (2012): Comparative study of depthdependent characteristics of equine and human osteochondral tissue from the medial and lateral femoral condyles. Osteoarthr. Cartil. 20, 1147-1151.

Nixon, A. J. and Cummings, J. F. (1994): Substance P immunohistochemical study of the sensory innervation of normal subchondral bone in the equine metacarpophalangeal joint. Am. J. Vet. Res. 55, 28-33.

Nixon, J. A., Begum, L., Mohammed, O. H., Huibregtse, B., O'Callaghan, M. M. and Matthews, G. L. (2011): Autologous chondrocyte implantation drives early chondrogenesis and organized repair in extensive full- and partial-thickness cartilage defects in an equine model. J. Orthop. Res. 29, 1121-1130. 
Ortved, K. F., Nixon, A. J., Mohammed, H. O. and Fortier, L. A. (2011): Treatment of subchondral cystic lesions of the medial femoral condyle of mature horses with growth factor enhanced chondrocyte grafts: A retrospective study of 49 cases. Equine Vet. J. 44, 606-613.

Piat, P., Richard, H., Beauchamp, G. and Laverty, S. (2012): In vivo effects of single intra-articular injection of $2 \%$ lidocaine or $0.5 \%$ bupivacaine on articular cartilage of normal horses. Vet. Surg. 41, 1002-1010.

Poole, A. R., Nelson, F., Dahlberg, L., Tchetina, E., Kobayashi, M., Yasuda, T., Laverty, S., Squires, G., Kojima, T., Wu, W. and Billinghurst, R. C. (2003): Proteolysis of the collagen fibril in osteoarthritis. Biochem. Soc. Symp. 70, 115-123.

Rikzalla, G., Reiner, A. and Bogoch, E. (1992): Studies of the articular cartilage proteoglycan aggrecan in health and osteoarthritis: evidence for molecular heterogeneity and extensive molecular changes in disease. J. Clin. Invest. 90, 2268-2277.

Sandler, E. A., Bramlage, L. R. and Embertson, R. M. (2002): Correlation of lesion size with racing performance in Thoroughbreds after arthroscopic treatment of subchondral cystic lesions of the medial femoral condyle: 150 cases (1989-2000). Proc. Assoc. Equine Pract. 48, 255-256.

Santschi, E. M., Williams, J. M., Morgan, J. W., Johnson, C. R., Bertone, A. L. and Juzwiak, J. S. (2015): Preliminary investigation of the treatment of equine medial femoral condylar subchondral cystic lesions with a transcondylar screw. Vet. Surg. 44, 281-288.

Steel, C. M. (2008): Equine synovial fluid analysis. Vet. Clin. North Am. Equine Pract. 24, 437-454.

Thonar, E. J. and Manicourt, D. H. (2001): Noninvasive markers in osteoarthritis. In: Moskowitz, R., Goldberg, V., Howell, D. S., Altmann, R. D. and Buckwalter, J. (eds) Osteoarthritis Diagnosis and Medical/Surgical Management. W. B. Saunders Company, Philadelphia. pp. 293-313.

Van Weeren, R. P. and Firth, E. C. (2008): Future tools for early diagnosis and monitoring of musculoskeletal injury: biomarkers and CT. Vet. Clin. North Am. Equine Pract. 24, 153-175.

Wallis, T. W., Goodrich, L. R., McIlwraith, C. W., Frisbie, D. D., Hendrickson, D. A., Trotter, G. W., Baxter, G. M. and Kawcak, C. E. (2008): Arthroscopic injection of corticosteroids into the fibrous tissue of subchondral cystic lesions of the medial femoral condyle in horses: a retrospective study of 52 cases (2001-2006). Equine Vet. J. 40, 461-467. 